
\title{
28 Research Square \\ The Effects of Public Health Emergencies on Altruistic Behaviors: Empirical Research on the COVID-19 Pandemic in China
}

Xiaotong Jin

Business School, Jilin University

Ershuai Huang

Business School, Jilin University

Wei Song ( $\nabla$ songweijlu@163.com )

Business School, Jilin University

Taiyang Zhao

School of Philosophy and Sociology, Jilin University

\section{Research Article}

Keywords: COVID-19 pandemic, empathy, sense of control, altruistic behavior

Posted Date: October 2nd, 2020

DOI: https://doi.org/10.21203/rs.3.rs-85880/v1

License: (c) (i) This work is licensed under a Creative Commons Attribution 4.0 International License.

Read Full License 


\section{Abstract}

Background: The coronavirus disease 2019 (COVID-19) pandemic constitutes a public health emergency that threatens all of society. During this time, it is important for people to help each other by providing support related to the viral components of the pandemic while also assisting with difficulties experienced at the social level. However, the nature of the infection itself puts everyone at risk, which may prevent altruistic behaviors. In other words, the pandemic has created a dilemma in which individuals may need to choose between their personal safety and continuing to help others. As such, this study explored how public health emergencies affect altruistic behaviors in the context of COVID-19.

Methods: Questionnaire surveys were distributed to 1508 residents from 31 provinces across China in February 2020 during the outbreak of COVID-19. Structural equation models were then implemented to test multiple research hypotheses using the obtained data.

Results: Findings showed that the severity of the pandemic had both positive and negative effects on altruistic behaviors. Empathy mediated the positive relationship between the severity of the pandemic and altruistic behavior, while the sense of control mediated the negative effect between the severity of the pandemic and altruistic behavior.

Conclusions: In the context of public emergencies such as the COVID-19 pandemic, altruistic behaviors can be enhanced by strengthening the factors of empathy and sense of control. These findings are useful for a government's altruistic behavior promotion and disaster risk management.

\section{Background}

As a public health emergency, the coronavirus disease 2019 (COVID-19) pandemic has not only resulted in the loss of life and property around the globe, it has also affected a variety of psychological states and behaviors. One such behavior is altruism. This is important due to the profound benefits achieved when individuals are willing to help others with both the viral and social aspects of the pandemic. For example, over 100,000 individuals in Guangdong province volunteered to serve urban and rural communities affected by COVID-19. Due to the selfless nature of this assistance, they were referred to as heroes in harm's way [1]. In Israel, many recovered COVID-19 patients also volunteered to help others who were hospitalized due to the virus [2]. The evidence shows that many individuals are willing to engage in altruistic behavior during the pandemic. However, the viral infection associated with COVID-19 can be deadly, thus putting everyone at risk. In this context, terror management theory posits that individuals will protect themselves from such threats by obtaining resources and avoiding risks [3]. For example, many residents in cities such as Madrid have remained home to protect themselves from issues related to the pandemic [4]. Because altruistic behavior occurs when individuals provide their own resources to help others [5], volunteers may bear the risks of infecting the virus. These concerns may create dilemmas between personal safety and the desire to provide assistance, thus preventing many instances of altruism 
over the course of the pandemic. This study explored the propensity for individuals to engage in altruistic behaviors during public health emergencies in the context of COVID-19.

At present, there are limits to the body of research outlining the relationship between emergencies and altruistic behavior. The biggest limitation is that most previous studies have explored altruistic behavior during social emergencies from a positive perspective. In the context of the Wenchuan earthquake in 2008 , for example, Rao et al. found that the degree of altruistic behavior increased with greater levels of residential devastation [6]. Anthropogenic disasters can also increase altruistic behavior. For example, after the September 11th attacks on the United States, many individuals donated blood and participated in voluntary organizations, especially those related to the crisis [7]. People often engage in altruistic behaviors during social emergencies in order to cope with negative effects while helping others out of dilemmas [8]. As with all social emergencies, the COVID-19 pandemic can cause serious harm at both the individual and societal levels, thus prompting altruistic behaviors targeted at the alleviation of suffering [6-8]. However, COVID-19 is associated with a variety of features that may not be present during other emergencies, including uncertainty, infection, and death. In this environment, people may avoid risks by limiting their contact with others. Indeed, Qian et al. found that many people prioritize themselves over helping others [9]. Because helping others may require interpersonal contact, this increases the risk of contracting the virus, thereby limiting the opportunity for altruism during the pandemic. Because previous studies have not examined the negative effects of social emergencies on altruistic behaviors, this study focused on this issue in the context of COVID-19, thus addressing a current theoretical gap.

More specifically, this study conducted an online questionnaire survey among 1,508 residents in 31 provinces of China during the pandemic outbreak (i.e., from February 10th to 15th). The obtained data were used to answer the following two research questions:

- Are people willing to engage in altruistic behavior during the pandemic outbreak?

- What psychological mechanism underlies the effects of the COVID-19 pandemic on altruistic behavior?

\section{Theoretical Background and Hypotheses}

\section{Altruistic Behavior During Social Emergencies}

Altruistic behavior refers to actions that help others at the cost of the helper[5]. Such behaviors have the following characteristics: (1) they benefit others, (2) they are voluntary, (3) the behavior has a certain awareness and clear purpose, and (4) the helper does not expect a return [10]. According to the theory of social information processing, the social environment may also affect altruistic behaviors [11], including the level of social support [12], social exclusion [13], and the nature of the social emergency to which one must respond [6, 7]. Regarding this latter element, an ancient proverb states that "more disaster makes a country prosperous," meaning that people tend to give generously and selflessly when disaster strikes 
[14]. Social emergencies thus constitute the most important factor related to altruistic behavior. As such, this study focused on how public health emergencies motivate altruistic behaviors in the context of COVID-19.

The current pandemic outbreak poses multiple psychological effects at the individual level, thus affecting altruistic behaviors. For instance, lives are continually threatened due to the increasing number of diagnoses, many of which have ended in death and other forms of misfortune. On one hand, previous studies have shown that unfortunate events often trigger empathy for those who are suffering, thus increasing altruistic behavior $[7,8,15]$. This suggests that the severity of the pandemic has a positive effect on these types of behaviors. On the other hand, the high rates of infection and death can trigger fear. In this context, terror management theory posits that individuals will protect themselves from COVID19 by obtaining resources and avoiding risks [3]. Altruistic behavior may thus be inhibited because helpers confront a variety of risks, even when attempting to donate resources [5]. This suggests that the severity of the pandemic has a negative effect altruistic behaviors. In sum, the severity of the pandemic may have both positive and negative effects in the study context.

\section{The Role of Empathy}

Empathy refers to the emotional response an individual has based on the emotional states of others, which instills feelings that they have been directly affected by the experience themselves [16]. Previous studies have shown that individual empathy can result from unfortunate events. For example, Batson and Ahmad stated that empathy is elicited when witnessing someone in an unfortunate situation [15], while Singer et al. found that it was easy to trigger empathy among individuals who were aware that others were suffering from misfortune [17]. As a public health emergency, COVID-19 poses several threats to life. This includes the soaring number of deaths and confirmed cases, which create widespread misfortune. Ebuenyi et al. had confirmed that unfortunate events can arouse empathy during the COVID-19 pandemic [18]. In this context, more severe aspects of the pandemic should create more empathy for those who are suffering. We therefore established the following hypothesis:

$\mathrm{H} 1$ : The severity of the pandemic is positively associated with empathy.

According to the empathy-altruistic hypothesis, higher levels of empathy are associated with higher levels of altruism [19]. Previous research has also confirmed this relationship in regard to altruistic behaviors. For example, Batson et al. found that empathy was the source of altruistic behavior [20]. Findlay et al. found that the same was true among children; that is, empathy is positively correlated with altruistic behavior [21]. We therefore established hypothesis 2, as follows:

H2: Empathy is positively associated with altruistic behavior.

Based on the above rationale, we propose that the severity of the pandemic can positively influence altruistic behavior. First, issues related to the severity of the pandemic can threaten life and create 
unfortunate situations, thus eliciting empathy for affected individuals $[15,17,18]$. As stated above, the empathy-altruistic hypothesis posits that higher levels of empathy are associated with higher altruism at the individual level [19-21]. We therefore established hypothesis 3, as follows:

H3: Empathy mediates the positive relationship between the severity of the pandemic and altruistic behavior.

\section{Role of Sense of Control}

In the pandemic context, individuals are not only concerned about the safety of others, but must also worry about their own safety. In this regard, sense of control is an important individual safety requirement [22]. Sense of control refers to the extent to which an individual perceives their ability to predict, explain, and affect the occurrence and development of external events, thus obtaining desired results [23]. Previous studies have found that sense of control has positive effects at the individual level. For example, high-level of sense of control can reduce the occurrence of mental illnesses such as depression and anxiety, which results in better mental and physical health [24]. However, sense of control is often affected by external threats. For example, Fritsche and Jonas found that death-related information was difficult for people to receive, thereby reducing sense of control $[25,26]$. The soaring death tolls related to COVID-19 may trigger an individual's fear of death, thus diminishing sense of control in a variety of contexts. In this regard, more severe of the pandemic may substantially reduce sense of control. We therefore established hypothesis 4 , as follows:

$\mathrm{H} 4$ : The severity of the pandemic is negatively associated with sense of control at the individual level.

Previous studies have shown that the lack of control can lead to negative psychological outcomes, including anxiety and restlessness [27]. This may induce a series of negative behavior. For example, Warburton et al. found that the lack of control increased anti-social behavioral tendencies [28, 29]. As such, individuals who perceive a lack of control may not only avoid altruistic behavior, but are also more likely to engage in antisocial behavior. Previous research has also shown that individuals with high level of sense of control may also have more psychological resources, thus increasing the tendency for altruistic behavior [30]. We therefore established hypothesis 5 , as follows:

H5: The sense of control is positively associated with altruistic behavior.

Based on the above discussion, we propose that the severity of the pandemic can negatively influence altruistic behavior in several ways. For example, soaring death tolls stemming from the pandemic may increase the fear of death, thereby reducing sense of control $[25,26]$. Individuals who perceive a lack of control will therefore engage in less altruistic behavior, which is mainly based on the following reasons. Firstly, Qian et al. found that people tend to prioritize themselves over the need to help others [9]. In this context, individuals may need to consider ways to restore control before helping others during the pandemic. Secondly, those who engage in altruistic behaviors may also consume their own resources, 
including time, money, and other valuables [5]. In turn, extended resource usage may result in insufficiencies to reply deal with the threat of posed by pandemic, which can further diminish sense of control. Finally, altruistic behaviors may increases the risk of infection with COVID-19, which also reduces sense of control [3]. We therefore established hypothesis 6, as follows:

H6: The sense of control mediates the negative relationship between the severity of the pandemic and altruistic behavior.

Figure 1 shows the theoretical model for the severity of the pandemic and altruistic behavior created for use in this study.

\section{Methods}

\section{Survey Sample}

total of 1,508 residents were surveyed in 31 provinces across China (excluding Hong Kong, Macau, and Taiwan). More specifically, online questionnaires were distributed via Credamo during February 2020 in order to obtain information about their actions and perceptions during the COVID-19 pandemic. Each respondent who completed a valid questionnaire received 10 yuan. See Table 1 for respondent characteristics.

Table 1. The sample characteristics 


\begin{tabular}{|c|c|c|c|c|c|c|c|}
\hline Items & Options & Sample & Percentage & Items & Options & Sample & Percentage \\
\hline \multirow[t]{2}{*}{ Gender } & Male & 838 & $55.6 \%$ & \multirow{4}{*}{$\begin{array}{l}\text { Personal } \\
\text { expenses } \\
\text { per } \\
\text { month }\end{array}$} & $<1000 \mathrm{RMB}$ & 525 & $34.8 \%$ \\
\hline & Female & 670 & $44.4 \%$ & & $\begin{array}{l}\text { 1000- } \\
\text { 2000RMB }\end{array}$ & 534 & $35.4 \%$ \\
\hline \multirow[t]{3}{*}{$\begin{array}{l}\text { Education } \\
\text { level }\end{array}$} & $\begin{array}{l}\text { High } \\
\text { school } \\
\text { or below }\end{array}$ & 347 & $23.0 \%$ & & $\begin{array}{l}2000- \\
3000 \mathrm{RMB}\end{array}$ & 229 & $15.2 \%$ \\
\hline & $\begin{array}{l}\text { Bachelor } \\
\text { degree }\end{array}$ & 1024 & $67.9 \%$ & & $>3000 \mathrm{RMB}$ & 220 & $14.6 \%$ \\
\hline & $\begin{array}{l}\text { Master } \\
\text { degree } \\
\text { or above }\end{array}$ & 137 & $9.1 \%$ & \multirow{4}{*}{$\begin{array}{l}\text { Personal } \\
\text { income } \\
\text { per } \\
\text { month }\end{array}$} & $<3000 \mathrm{RMB}$ & 568 & $37.7 \%$ \\
\hline \multirow[t]{3}{*}{ Age } & $<25$ & 703 & $46.6 \%$ & & $\begin{array}{l}\text { 3000- } \\
\text { 6000RMB }\end{array}$ & 551 & $36.5 \%$ \\
\hline & $25-40$ & 705 & $46.8 \%$ & & $\begin{array}{l}\text { 6000- } \\
\text { 9000RMB }\end{array}$ & 243 & $16.1 \%$ \\
\hline & $>40$ & 100 & $6.6 \%$ & & $>9000 \mathrm{RMB}$ & 146 & $9.7 \%$ \\
\hline
\end{tabular}

\section{Measures}

The independent variable was the severity of the pandemic (SP). This study selected pandemic-related data released by the Health Commission of the People's Republic of China on the day the subjects answered the question designed to measure SP. Data were divided into four categories, including the number of newly confirmed cases, cumulative number of confirmed cases, death toll, and number of cured cases. However, the death tolls and numbers of cured cases were zero in many cities where the pandemic was not considered serious. We therefore used the number of newly confirmed cases per province (NNP), cumulative number of confirmed cases per province (CNP), number of newly confirmed cases per city (NNC), and cumulative number of confirmed cases per city (CNC) to create an index for SP. We then matched the SP index to each participant depending on the date, city, and province recorded by Credamo.

The independent variable was altruistic behavior $(A B)$. As existing scales designed to measure $A B$ are based around regular daily life [31], they cannot be used in special situations such as a public health emergencies. This study compiled three items to measure $A B$ based on both its definition and specific issues related to the COVID-19 pandemic. AB was then measured on a 7-point Likert scale.

The mediating variables were set as empathy (EM) and sense of control (SC). To measure EM, we used the five-item situational empathy scale developed by Toi and Batson, which was adapted to fit the COVID19 context [32]. To measure SC, we used the three-item situational control scale developed by Fritsche 
and Jonas [25]. Both EM and SC were rated using a 5-point Likert scale. Items connected to these variables are shown in Table 2.

Table 2. Items related to the study variables

\begin{tabular}{|ll|}
\hline Variable & Items \\
\hline Severity of the & NNP: Number of newly confirmed cases per province \\
\hline CNP: Cumulative number of confirmed cases per province \\
\hline NNC: Number of newly confirmed cases per city \\
\hline CNC: Cumulative number of confirmed cases per city \\
\hline $\begin{array}{l}\text { EM1: During the pandemic, I was worried about other people and their } \\
\text { situations }\end{array}$ \\
$\begin{array}{l}\text { EM2: During the pandemic, I am very concerned about others and their } \\
\text { situations }\end{array}$ \\
$\begin{array}{l}\text { EM3: During the pandemic, I feel emotional resonance about the dilemmas } \\
\text { encountered by others }\end{array}$ \\
$\begin{array}{l}\text { EM4: During the pandemic, I felt sympathy for the misfortunes encountered } \\
\text { by others }\end{array}$ \\
\hline $\begin{array}{l}\text { EM5: During the pandemic, I was inspired by the great deeds of others } \\
\text { Sense of Control (SC) }\end{array}$ & $\begin{array}{l}\text { SC1: At this moment, I feel helpless (R) } \\
\text { SC2: At this moment, I feel powerless (R) }\end{array}$ \\
\hline $\begin{array}{l}\text { SC3: At this moment, I feel a lack of control (R) } \\
\text { (AB) }\end{array}$ & $\begin{array}{l}\text { AB1: In order to fight the pandemic, how many days are you willing to } \\
\text { volunteer? }\end{array}$ \\
$\begin{array}{l}\text { AB2: In order to fight the pandemic, are you willing to sacrifice your own } \\
\text { interests to help others? }\end{array}$ \\
$\begin{array}{l}\text { AB3: In order to fight the pandemic, are you willing to take risks to help } \\
\text { others? }\end{array}$ \\
\hline
\end{tabular}

\section{Results}

Reliability, Validity, and Measurement Model

This study conducted confirmatory-factor and reliability analyses to test the measurement model (Table 3). The Cronbach'sa coefficients for SP, EM, SC, and AB were all greater than 0.8 , while the AVE was greater than 0.5 , and the $\mathrm{CR}$ was greater than 0.8 . This indicates that the measurement tool was 
sufficiently reliable [33,34]. This study also used a structural equation model to test the discriminant validity of each variable. Because the large sample size may have led to chi-square expansion, we adopted the Bollen-Stine method to calibrate the model [35]. The calibrated model indices are shown in Table 3. The model fitting index of the measurement model met the minimum requirements $\left(c^{2} / d f<4\right.$, RMESA $<0.1, \mathrm{CF}|>0.9,| \mathrm{F}|>0.9, \mathrm{TL}|>0.9[36])$.

Table 3. Reliability and validity

\begin{tabular}{|c|c|c|c|c|c|}
\hline Variable & Items & Standardized Factor Loading & C.R. & AVE & Cronbach's a \\
\hline \multirow{4}{*}{ SP } & NNP & 0.942 & \multirow{4}{*}{0.905} & \multirow{4}{*}{0.708} & \multirow{4}{*}{0.911} \\
\hline & CNP & 0.967 & & & \\
\hline & NNC & 0.709 & & & \\
\hline & $\mathrm{CNC}$ & 0.711 & & & \\
\hline \multirow{5}{*}{ EM } & EM1 & 0.668 & \multirow{5}{*}{0.855} & \multirow{5}{*}{0.542} & \multirow{5}{*}{0.854} \\
\hline & EM2 & 0.698 & & & \\
\hline & EM3 & 0.749 & & & \\
\hline & EM4 & 0.796 & & & \\
\hline & EM5 & 0.764 & & & \\
\hline \multirow[t]{3}{*}{ SC } & SC1 & 0.844 & \multirow{3}{*}{0.856} & \multirow{3}{*}{0.666} & \multirow{3}{*}{0.851} \\
\hline & SC2 & 0.882 & & & \\
\hline & SC3 & 0.712 & & & \\
\hline \multirow[t]{3}{*}{$A B$} & AB1 & 0.526 & \multirow{3}{*}{0.826} & \multirow{3}{*}{0.624} & \multirow{3}{*}{0.810} \\
\hline & AB2 & 0.896 & & & \\
\hline & AB3 & 0.893 & & & \\
\hline \multicolumn{6}{|c|}{ Model Fit: $\chi^{2} / \mathrm{df}=1.150, \mathrm{RMSEA}=0.010, \mathrm{CFI}=0.999, \mathrm{IFI}=0.999, \mathrm{TLI}=0.999$} \\
\hline $\begin{array}{l}\text { C.R. }=\text { Com } \\
\text { Approxim }\end{array}$ & $\begin{array}{l}\text { te Reli } \\
\text { h, CFI= }\end{array}$ & $\begin{array}{l}\text { ty, AVE }=\text { Average Variance Extr } \\
\text { parative Fit Index, IFI= Increme }\end{array}$ & $\begin{array}{l}\text { ISEA }= \\
\text { ndex, }\end{array}$ & $\begin{array}{l}\text {-mean- } \\
\text { Tucker }\end{array}$ & $\begin{array}{l}\text { are Error of } \\
\text { vis Index. }\end{array}$ \\
\hline
\end{tabular}

We also applied the diagonal matrix analysis method to test the discriminant validity (Table 4). As shown, the value on the diagonal represented the square heel of the AVE, while the value under the diagonal represents the correlation coefficient between variables. This shows that the variables are better 
explained by the variable to which they belong than other variables when the value on the diagonal is greater than the value under the diagonal [34]. As presented in Table 4, this study was shown to have good discrimination validity.

Table 4. Correlation and discriminant validity

\begin{tabular}{|lllll|}
\hline & SP & EM & SC & $A B$ \\
SP & $\mathbf{0 . 8 4 1}$ & & & \\
EM & $0.138^{\star \star}$ & $\mathbf{0 . 7 3 6}$ & & \\
SC & $-0.131^{\star \star}$ & 0.024 & $\mathbf{0 . 8 1 6}$ & \\
\hline$A B$ & -0.035 & $0.168^{\star \star}$ & $0.126^{* \star}$ & $\mathbf{0 . 7 9 0}$ \\
\hline
\end{tabular}

Note: ${ }^{* *} \mathrm{p}<.01$ (two-tailed)

\section{Structural Equation Model Analysis}

This study used the AMOS 24.0 software to build a structural equation model. As mentioned above, the large sample size may have led to chi-square expansion. We thus adopted the Bollen-Stine method to calibrate the model [35]. The results are shown in Table 5 and Figure 2. As presented, SP had a significant positive effect on EM $(\beta=0.060, p<.001)$, thus confirming $\mathrm{H} 1$. On the other hand, SP had a significant negative effect on $S C(\beta=-0.093, p<.001)$, thus confirming $H 4$. Further, EM had a significant positive effect on $A B(\beta=0.248, p<.001)$, thus confirming $H 2$. SC also had a significant positive effect on $A B(\beta=0.072$, $p<.01)$, thus confirming H5. However, SP had no significant effects on $A B(\beta=-0.020, p>05)$, thus indicating the existence of both negative and positive effects.

Table 5. Path analysis

\begin{tabular}{|lllllll|}
\hline Path & & & Standardized Estimate & S.E. & T-Value & $p$ \\
$\mathrm{SP}$ & $\rightarrow$ & $\mathrm{EM}$ & 0.060 & 0.011 & 5.190 & 0.000 \\
$\mathrm{SP}$ & $\rightarrow$ & $\mathrm{SC}$ & -0.093 & 0.016 & -5.725 & 0.000 \\
$\mathrm{EM}$ & $\rightarrow$ & $\mathrm{AB}$ & 0.248 & 0.035 & 6.995 & 0.000 \\
$\mathrm{SC}$ & $\rightarrow$ & $\mathrm{AB}$ & 0.072 & 0.023 & 3.103 & 0.002 \\
$\mathrm{SP}$ & $\rightarrow$ & $\mathrm{AB}$ & -0.020 & 0.013 & -1.579 & 0.114 \\
\multicolumn{5}{l}{ Model Fit: $\chi^{2} / \mathrm{df}=1.150, \mathrm{RMSEA}=0.010, \mathrm{CFI}=0.999, \mathrm{IFI}=0.999, \mathrm{TLI}=0.999$} \\
\hline
\end{tabular}


The bootstrap method with bias correction was used to test the mediating effects of EM and SC between $\mathrm{SP}$ and $\mathrm{AB}$ [37]. This method included procedures that computed $95 \%$ confidence intervals (Cls) for the total, indirect, and direct effects. If the $95 \%$ confidence interval does not contain 0 , then the mediation effect is significant [37]. The results are shown in Table 6. After controlling for age, sex, education, personal expenses per month, and personal income per month, EM had a significantly mediating effect between SP and $A B(\beta=0.018,95 \% \mathrm{Cl}: 0.010$ to 0.031$)$, thus confirming $\mathrm{H} 3$. Next, SC had a significant mediating effect between $S P$ and $A B(\beta=-0.016,95 \% \mathrm{Cl}:-0.026$ to -0.009$)$, thus confirming $\mathrm{H} 6$. However, the total effect of SP on $A B$ was not significant ( $\beta=0.003,95 \% \mathrm{Cl}$ : -0.011 to 0.017 ), thus indicating that the relationship between SP and AB was obscured by the mediating effects of EM and SC.

Table 6. The path coefficient of mediating effect

\begin{tabular}{|c|c|c|c|c|c|}
\hline \multirow[t]{2}{*}{ Path } & \multirow[t]{2}{*}{ Effect } & \multirow{2}{*}{$\begin{array}{l}\text { Standardized } \\
\text { Estimate }\end{array}$} & \multirow[t]{2}{*}{ S.E. } & \multicolumn{2}{|l|}{$95 \% \mathrm{Cl}$} \\
\hline & & & & BootLLCI & BootULCI \\
\hline \multirow{3}{*}{$\begin{array}{l}S P \rightarrow(E M \text { or } \\
S C) \rightarrow A B\end{array}$} & Total effect & 0.003 & 0.007 & -0.011 & 0.017 \\
\hline & $\begin{array}{l}\text { Indirect effect } \\
\text { (EM) }\end{array}$ & 0.018 & 0.005 & 0.010 & 0.031 \\
\hline & $\begin{array}{l}\text { Indirect effect } \\
\text { (SC) }\end{array}$ & -0.016 & 0.005 & -0.026 & -0.009 \\
\hline $\mathrm{SP} \rightarrow \mathrm{AB}$ & direct effect & -0.046 & 0.025 & -0.095 & 0.003 \\
\hline
\end{tabular}

\section{Discussion}

\section{Theoretical Contributions}

Most research on issues related to COVID-19 have focused on mental health [38, 39], with only a few studies having explored altruistic behavior [40]. As such, this study's findings add to the broader literature by describing how people may respond to the COVID-19 pandemic, specifically in regard to the relationships between the severity of the pandemic, altruistic behavior, empathy, and the sense of control.

Most previous studies on the relationship between emergencies and altruistic behaviors have focused on the positive aspects [6, 7]. However, the COVID-19 pandemic constitutes a unique public emergency due to its associations with infection and death, which have both positive and negative effects on altruistic behavior. This study constructed a dual mediation model for "the severity of pandemic-empathy/sense of control-altruistic behavior", which was subjected to theoretical and empirical analyses based on the 
data related to the COVID-19 pandemic in China. Our conclusions thus complement the single effect of emergencies on altruistic behaviors.

\section{Practical Implications}

Previous studies have shown that continuous empathy can lead to emotional exhaustion, which causes empathy fatigue [41]. Government entities should thus take measures to reduce empathy fatigue, thereby increasing altruistic behavior. Previous research has also shown that social support can reduce emotional exhaustion [39]. As such, governments should vigorously publicize anti-pandemic response measures through the media. This will advance the general perception of social support, reduce empathy fatigue, and increase altruistic behavior.

This study showed that the severity of the pandemic had a negative effect on the sense of control. In this regard, enhancing the sense of control can help individuals alleviate and cope with anxieties stemming from pandemic threats [3]. Notably, a previous study showed that the individual sense of control can be restored through external support [3, 42]. In this regard, additional government resources should be distributed in areas severely affected by the pandemic, thus enhancing the sense of control while increasing altruistic behaviors under the premise of engaging in self-protection.

\section{Limitations and Future Research Directions}

This study had some limitations. First, it demonstrated the relationship between the severity of the pandemic and altruistic behavior via theoretical construction and empirical testing. However, the relationship between these factors may be influenced by boundary conditions. Future research is thus needed. Second, this study only explored altruistic behaviors in the context of pandemic severity. Under the pressures of COVID-19, however, altruistic behaviors may be affected by other factors, including the credibility of charitable organizations and the individual self-concept, which can be studied in the future.

\section{Conclusion}

This study surveyed 1,508 residents to explore how the severity of the pandemic affected altruistic behavior in addition to the dual mediating role of empathy and sense of control in this process. We found that the severity of the pandemic had both negative and positive effects on altruistic behaviors. More specifically, empathy mediated the positive relationship between the severity of the pandemic and altruistic behavior, while the sense of control mediated the negative effect between the severity of the pandemic and altruistic behavior.

\section{Declarations}


Acknowledgements

Not applicable

\section{Authors' contributions}

All authors contributed significantly to the concept of this study. Conceptualization, XTJ and ESH; methodology, ESH and WS; investigation, ESH and WS; data curation and data analysis, ESH; writingoriginal draft preparation, ESH and TYZ; writing-review and editing, ESH and WS; project administration, XTJ and TYZ; funding acquisition, XTJ and TYZ.

\section{Funding}

This study was funded by the National Natural Science Foundation of China (No. 71902069, 71872070), Social Science Fund of Jilin (No. 2019c31) and Preferential Postdoctoral Fund of Jilin.

\section{Availability of data and materials}

The datasets used during the current study are available from the corresponding author on reasonable request.

\section{Ethics approval and consent to participate}

Not applicable

\section{Consent for publication}

Not applicable. The survey was anonymous for all participants.

\section{Competing interests}

The authors declare no conflict of interest.

\section{References}

1. Over 100,000 volunteers fight against COVID-19 in Guangdong: http://www.newsgd.com/news/exclusive/content/2020-03/06/content_190511876.htm (accessed on 6 March 2020).

2. Feature: Recovered COVID-19 patients volunteer to help at Israeli hospital: http://www.xinhuanet.com/english/2020-07/14/c_139209915.htm (accessed on 14 July 2020)

3. Li M, Zhao TY, Huang ES, Li JN. How does a public health emergency motivate people's impulsive consumption? An empirical study during the COVID-19 outbreak in china. Int J Environ Res Public Health. 2020;17(14):5019- 
4. Madrid asks residents to stay home as COVID-19 cases rise: http://www.xinhuanet.com/english/2020-08/22/c_139308697.htm (accessed on 22 August 2020).

5. Fehr E, Fischbacher U. The nature of human altruism. Nature, 2003;425(6960):785-791.

6. Rao L, Han R, Ren XP, Bai X W, Zheng R, Liu H, Wang ZJ, Li JZ, Zhang K, Li S. Disadvantage and prosocial behavior: The effects of the wenchuan earthquake. Evol Hum Behav. 2011;32:63-69.

7. Piferi R, Jobe R, Jones W. Giving to others during national tragedy: The effects of altruistic and egoistic motivations on long-term giving. J Soc Pers Relat. 2006;23(1):171-184.

8. Staub E, Vollhardt JR. Altruism born of suffering: The roots of caring and helping after victimization and other trauma. Am J Orthopsychiatry. 2008;78(3):267-280.

9. Xu Q, Kwan C, Zhou X. Helping yourself before helping others: How sense of control promotes charitable behaviors. J Consum Psychol. 2020;30(3):486-505

10. Piliavin JA, Charng H. Altruism: A review of recent theory and research. Annu Rev Sociol. 1990;16:27-65.

11. Salancik GR, Pfeffer J. A social information processing approach to job attitudes and task design. Adm Sci Q. 1978;23(2):224-253

12. Cropanzano R, Mitchell MS. Social exchange theory: An interdisciplinary review. J Manage. 2005;31(6):874-900.

13. Twenge JM, Ciarocco NJ, Baumeister RF, DeWall CN, Bartels JM. Social exclusion decreases prosocial behavior. J Pers Soc Psychol. 2007;92(1):56-66.

14. Li Y, Li H, Decety J, Lee K. Expriencing a natural diaster alters children's altruistic giving. Psychol Sci. 2013;24(9):1686-1695.

15. Batson CD, Ahmad N. Empathy-induced altruism in a prisoner's dilemma II: what if the target of empathy has defected?. Eur J Soc Psychol. 2001;31(1):25-

16. Bernhardt BC, Singer T. The neural basis of empathy. Annu Rev Neurosci. 2012;35(1):1-23.

17. Singer T, Seymour B, O'Doherty JP, Stephan KE, Dolan RJ, Frith CD. Empathic neural responses are modulated by the perceived fairness of others. Nature, 2006;439(7075):466-469.

18. Ebuenyi ID, Smith EM, Holloway C, Jensen R, D'Arino L, MacLachlan M. COVID-19 as social disability: the opportunity of social empathy for empowerment. BMJ Glob Health. 2020;5(8):1-3.

19. Batson CD, Shaw LL. Evidence for altruism: Toward a pluralism of prosocial motive. Psychol Inq. 1991;2(2):107-122.

20. Batson GJ, Mattew TR, Brannect BH. Empathy and the collective good: Caring for on of the others in a social dilemmas. J Pers Soc Psychol.1995, 68(4):619-631

21. Findlay LC, Girardi A, Coplan RJ. Links between empathy, social behavior, and social understanding in early childhood. Early Childhood Res Q. 2006;21(3):347-359.

22. Daniels $M$. The development of the concept of self-actualization in the writings of abraham maslow. Curr Psychol Rev. 1982;2(1):61-75 
23. Burger JM. Negative reactions to increases in perceived personal control. J Pers Soc Psychol. 1989;56(2):246-256.

24. Infurna FJ, Gerstorf D, Ram N, Schupp J, Wagner GG. Long-term antecedents and outcomes of perceived control. Psychol Aging, 2011;26(3):559-575.

25. Fritsche I, Jonas $E$. The role of control motivation in mortality salience effects on ingroup support and defense. J Pers Soc Psychol. 2008;95(3):524-541.

26. Liu WM, Wang JY, Shao JP. An elaboration on the underlying mechanisms through which consumers' desire for product touch forms: A cognitive experiential perspective. Acta Psychol Sin. 2016;46(11):410-422.

27. Whalen PJ. Fear, vigilance, and ambiguity: Initial neuroimaging studies of the human amygdala. Curr Dir Psychol Sci. 1998;7(6):177-188.

28. Warburton WA, Williams KD, Cairns DR. When ostracism leads to aggression: The moderating effects of control deprivation. J Exp Soc Psychol .2006;42(2):213-220

29. Guo X, Egan V, Zhang J. Sense of control and adolescents' aggression: The role of aggressive cues. Psych J. 2016;5(4):263-274.

30. Rudolph U, Roesch S, Greitemeyer T, Weiner B. A meta-analytic review of help giving and aggression from an attributional perspective: Contributions to a general theory of motivation. Cogn Emot. 2004;18(6):815-848.

31. Wrightsman LS. Assumptions about human nature: A social psychological analysis. Monterey, CA: Brooks/Cole, 1974.

32. Toi M, Batson CD. More evidence that empathy is a source of altruistic motivation. J Pers Soc Psychol. 1982;43(2):281-292.

33. McAllister DJ, Bigley GA. Work context and the definition of self: How organizational care influences organization-based self-esteem. Acad Manage J. 2002;45(5):894-904.

34. Fornell C, Larcker DF. Structural equation models with unobservable variables and measurement error: algebra and statistics. J Mark Res.1981;18(3):382-388.

35. Bollen KA, Stine RA. Bootstrapping goodness-of-fit measures in structural equation models. Sociol Metheods Res. 1992;21(2):205-229.

36. Hu L, Bentler PM. Fit indices in covariance structure modeling:Sensitivity to underparameterized model misspecification. Psychol Methods, 1998;3(4):424-453.

37. Preacher KJ, Rucker DD, Hayes AF. Addressing moderated mediation hypotheses: Theory, methods, and prescriptions. Multivariate Behav Res 2007;42(1):185-227.

38. Feng Y, Zhong M, Yang Z, Gu W, Dong D, Qiao Z. When altruists cannot help: the influence of altruism on the mental health of university students during the COVID-19 pandemic. Global Health. 2020;16(1):1-8.

39. Auerbach J, Miller BF. COVID-19 Exposes the cracks in our already fragile mental health system. Am J Public Health. 2020;110:969-970. 
40. Maftei A. The more you have, the less you give? Prospective donation behavior for COVID-19 causes. Rom J Psychol. 2020;22(1):15-20.

41. Hodges SD, Klein KJK. Regulating the costs of empathy: The price of being human. J Socio-Econ. 2001;30(5):437-452.

42. Boscarino JA, Figley CR, Adams RE. Compassion fatigue following the September 11 terrorist attacks: A study of secondary trauma among New York city social workers. Int J Emerg Ment Health. 2004;6(2):57-66.

Figures

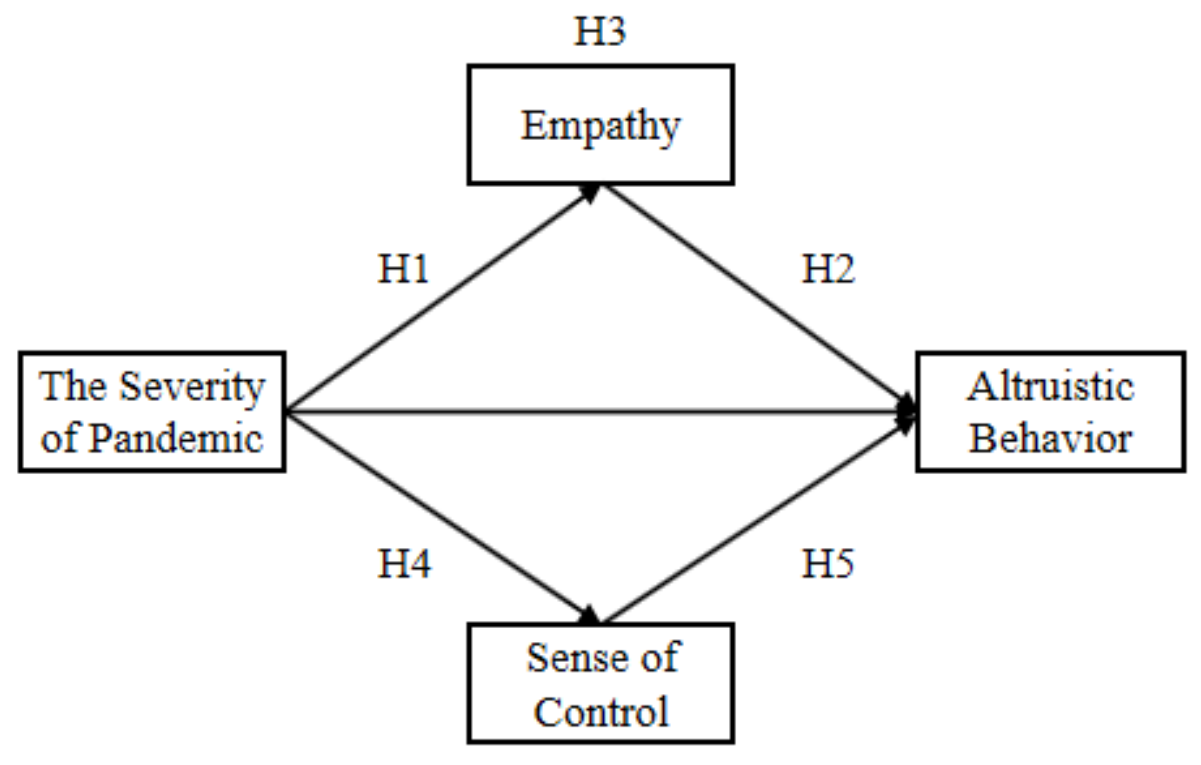

H6

\section{Figure 1}

Theoretical model 


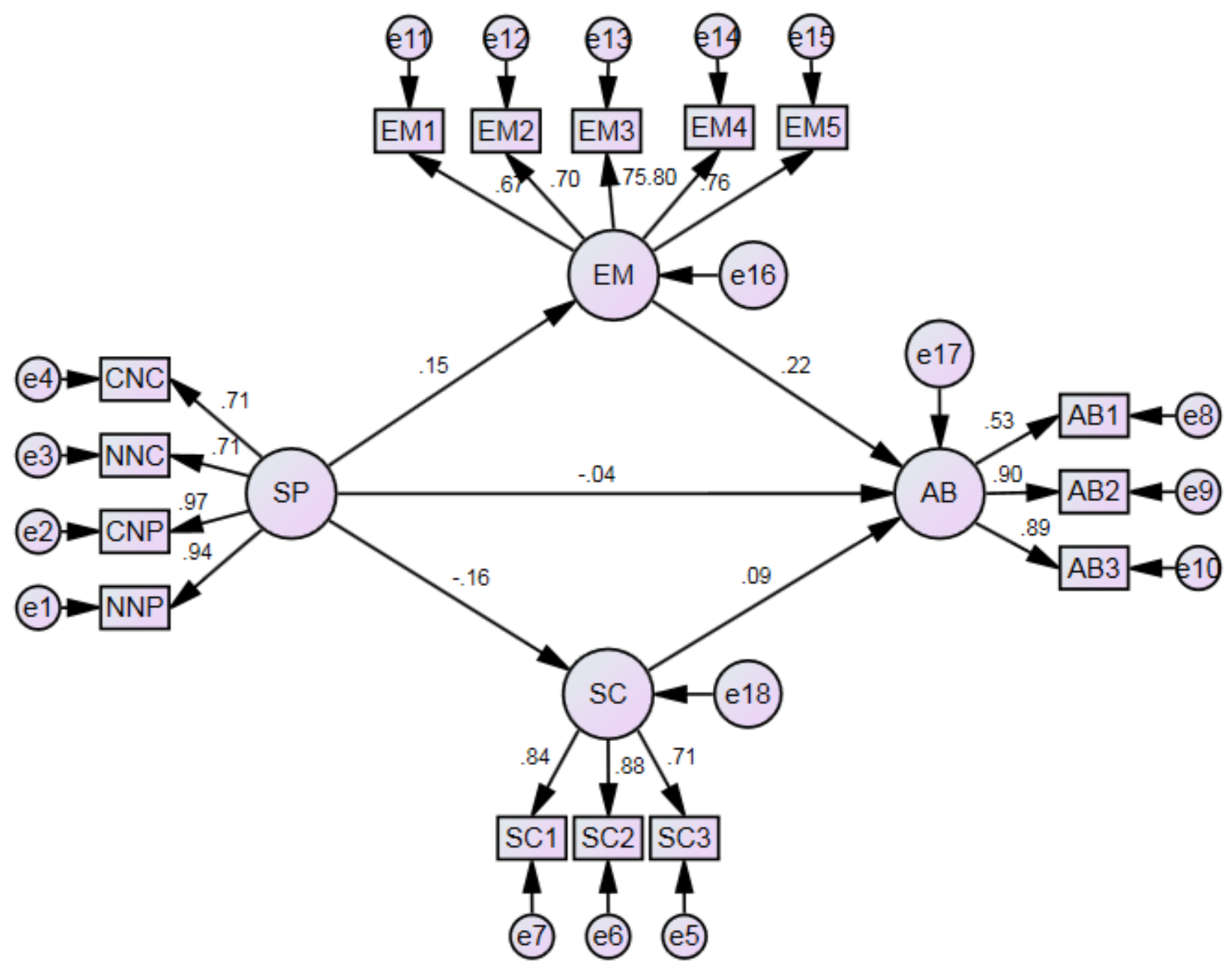

Figure 2

Structural equation model diagram 